\title{
A CONTRIBUIÇÃO DA PRODUÇÃO DE VÍDEOS DIGITAIS POR DISCENTES DE UMA ESCOLA MUNICIPAL NA CONSTRUÇÃO DO CONHECIMENTO CONTEXTUALIZADO NO ENSINO DE CIÊNCIAS
}

\author{
PRODUCCIÓN DE CONTRIBUCIÓN DE VÍDEO DIGITAL PARA LOS \\ ESTUDIANTES DE UNA ESCUELA MUNICIPAL PARA CONSTRUIR \\ CONOCIMIENTO CONTEXTUALIZADO EN LA ENSEÑANZA DE LAS \\ CIÊECIAS
}

\begin{abstract}
THE CONTRIBUTION OF THE PRODUCTION OF DIGITAL VIDEOS BY DISCIPLES OF A MUNICIPAL SCHOOL IN THE CONSTRUCTION OF CONTEXTUALIZED KNOWLEDGE IN SCIENCE TEACHING
\end{abstract}

\author{
Sebastiao Silva VIEIRA ${ }^{1}$
}

RESUMO: Este trabalho apresenta uma pesquisa de intervenção e participante que analisa como a produção de vídeos digitais por discentes de uma escola municipal traz contribuições para a construção do conhecimento contextualizado no ensino de ciências. Para isso foram usadas referências para atender a quatro campos temáticos: o uso das tecnologias digitais no contexto escolar; a contextualização dos conteúdos no ensino de ciências; comunicação e mediação na escola; e por fim a produção de vídeo digital no ensino de ciências. A metodologia utilizada possui caráter qualitativo, empregando entrevistas semiestruturadas e observação participante. Anteriormente ao início dos trabalhos dos discentes, foram realizadas oficinas de criação de vídeo digitais; em seguida, foi realizada uma entrevista semiestruturada, na fase pós-produção, com os discentes e o docente. Os resultados mostram que a produção de vídeos digitais trouxe contribuições significativas para os discentes, desde a participação na oficina de produção de vídeos, até a etapa de conclusão e apresentação do vídeo digital em sala de aula. Com isso, os discentes utilizaram a produção do vídeo digital como uma metodologia diferenciada, fonte de pesquisa e produção de conhecimento. Discentes realizadores, aprendizes e autores na elaboração do vídeo, pesquisando informações referentes ao conteúdo, realizando leituras, planejando a produção, o "roteiro", acompanhando a montagem, utilizando as tecnologias digitais na produção, divulgando e participando de debates de forma coletiva. Os mesmos construíram os conhecimentos propostos no ensino de ciências, trouxeram para a prática o conteúdo curricular estudado e com isso reforçaram a discussão sobre o uso e produção do vídeo digital como instrumento educacional.

\footnotetext{
1 Universidade Federal de Pernambuco (UFPE), PE - Brasil. Mestre em Educação Matemática e Tecnológica - EDUMATEC - UFPE. Aluno especial do Programa de Pós Graduação em Educação, da UFPE (2010) e do Programa de Pós Graduação em Educação Matemática e Tecnológica - EDUMATEC da Universidade Federal de Pernambuco - UFPE (2013). Atuou como docente no ensino fundamental anos finais na rede municipal de Itapissuma, onde desenvolve pesquisa na área de tecnologias na educação, trabalhando os recursos tecnológicos e audiovisuais no desenvolvimento da aprendizagem. Atuou em tutoria em Ead na UAB/UFRPE, no curso de Letras no Pólo Afrânio -PE e UAB/ UFPE e CONECT[e] - Inovação Educacional no curso de formação em Ead para tutores. E-mail: sebastianfacig@gmail.com
} 
PALAVRAS-CHAVE: Vídeo digital. Conhecimento contextualizado. Tecnologias digitais. Ensino de ciências.

RESUMEN: Este artículo presenta una investigación de la intervención y análisis de los participantes como la producción de vídeos digitales por los estudiantes de una escuela municipal aporta contribuciones a la construcción del conocimiento contextualizado en la enseñanza de la ciencia. Por esta mención se han utilizado para tratar cuatro áreas temáticas: el uso de las tecnologías digitales en el contexto escolar; contextualización de los contenidos de la educación científica; la comunicación y la mediación en las escuelas; y, finalmente, la producción de vídeo digital en la educación científica. La metodología utilizada cualitativa, mediante entrevistas semiestructuradas y observación participante. Anteriormente, los inicios de los trabajos de los estudiantes, se llevaron a cabo talleres para crear vídeo digital, a continuación, una entrevista semiestructurada se llevaron a cabo en la fase de post-producción, con los estudiantes y el profesor. Los resultados muestran que la producción de vídeo digital trajo contribuciones significativas a los estudiantes de participar en el taller de producción de vídeos, a la etapa de terminación y presentación de vídeo digital en el aula. Con esto, los estudiantes utilizaron la producción de vídeo digital como una metodología diferente, fuente de investigación y producción de conocimiento. Cineastas estudiantes, aprendices y autores en la preparación del vídeo, la búsqueda de información sobre el contenido, la realización de lecturas, la planificación de la producción, la "hoja de ruta", después de la asamblea, el uso de las tecnologías digitales en la producción, promover y participar en los debates de manera colectiva. Construyeron el conocimiento propuesto en enseñanza de las ciencias llevó a la práctica el contenido de los programas estudiados y por lo tanto refuerza la discusión sobre el uso y producción de vídeo digital como una herramienta educativa.

PALABRAS CLAVE: Vídeo digital. Conocimiento contextualizado. Tecnologías digitales. La educación científica.

ABSTRACT: This work presents an intervention research and participant that analyzes how the production of digital videos by students of a municipal school brings contributions to the construction of the knowledge contextualized in the teaching of sciences. For this purpose, references were used to cover four thematic areas: the use of digital technologies in the school context; The contextualization of contents in science education; Communication and mediation in school; And finally the production of digital video in science education. The qualitative methodology used, using semistructured interviews and participant observation. Previously, the beginnings of the work of the students, workshops were created to create digital video, then a semistructured interview was carried out, in the post-production phase, with the students and the teacher. The results show that the production of digital videos have brought significant contributions to the students since participating in the workshop of video production, to the stage of conclusion and presentation of digital video in the classroom. With this, the students used the production of digital video as a differentiated methodology, source of research and production of knowledge. Participants, directors, learners and authors in the elaboration of the video, searching information related to the content, performing readings, planning the production, the "script", accompanying the assembly, using digital technologies in production, disseminating and participating in debates collectively. They constructed the knowledge 
proposed in science teaching and brought the curricular content studied into practice, reinforcing the discussion about the use and production of digital video as an educational tool.

KEYWORDS: Digital video. Contextual knowledge. Digital technologies. Science teaching.

\section{Educação contemporânea, tecnologias digitais e ensino de ciências}

A estrutura da escola e da Educação ao longo do tempo vem aos poucos se modificando; a escola ainda carrega "em sua cultura" toda uma lógica tradicionalista e metodológica. Atualmente, na era da contemporaneidade, a escola como instituição de ensino, visando à formação integral do sujeito, vem se adaptando às novas culturas atuais, principalmente com o uso das novas tecnologias de informação e comunicação. Na concepção de Silva e Correia (2014, p. 27) "nesse cenário, cabe refletir sobre a importância das novas tecnologias para a aprendizagem. Elas realmente podem contribuir para esse processo ou isso é algo utópico, ilusório? Os educandos só aprendem da forma como se aprendia trinta anos atrás?". Em busca de responder a esses questionamentos, Zuin (2010, p. 964) coloca que:

\footnotetext{
As respostas para essas questões se refiram ao fato de que tais transformações proporcionadas pelo desenvolvimento das forças produtivas, notadamente as de âmbito tecnológico, ocorrem numa tal velocidade que dificultam a composição de reflexões mais elaboradas sobre tal processo. Provavelmente, diante da rapidez do desenvolvimento dessas tecnologias, a expressão, tão comumente usada, de que estamos dentro do "olho do furacão", não represente apenas uma figura de linguagem.
}

O grande objetivo da educação na contemporaneidade é integrar a escola a essas novas situações de aprendizagem, fazendo que ela insira em sua cultura escolar novas metodologias e dinamização de ensino e aprendizagem, transformando os discentes em atores autônomos e capazes de construir saberes práticos associados com os conteúdos ensinados pela escola, transformando as informações de cada disciplina ensinada em conhecimento.

\section{O vídeo digital em educação}


O vídeo digital no contexto educacional pode ser uma interessante alternativa para o ensino e aprendizagem: os vídeos dinamizam as aulas, e a assimilação dos conteúdos é mais prazerosa. Produzir e compartilhar vídeos atualmente na cultura digital é algo cada vez mais frequente, os discentes produzem e compartilham seus conteúdos na rede utilizando como auxílio as novas tecnologias digitais, tais como: celular (smartphone), tablets, câmeras digitais. Segundo Marcondes Filho (1995, p. 23) "na era digital o homem possui uma relação diferente com o seu meio e suas ideias".

Um discente que não compreender um assunto discutido em sala de aula, através de textos e exposição oral, encontra dificuldade na compreensão. Porém, se esse mesmo conteúdo for apresentado a ele por meio dos recursos ou produção audiovisual, esses estímulos visuais e sonoros podem fazer muita diferença em sua aprendizagem.

Para Moran, Masetto e Behrens (2012, p. 38) “a televisão e o vídeo são também escrita. Os textos, as legendas, as citações aparecem cada vez mais na tela, principalmente nas traduções (legendas de filmes) e nas entrevistas com estrangeiro".

Televisão e vídeo são sensoriais, visuais, linguagem falada, linguagem musical e escrita. Linguagens que interagem superpostas, interligadas, somadas e de todas as maneiras. Televisão e vídeo nos seduzem, informam, entretêm, projetam em outras realidades (no imaginário), em outros tempos e espaços. (MORAN, MASETTO e BEHRENS, 2012, p. 23)

O vídeo, juntamente com a televisão, tem um papel muito importante no processo de aprendizagem dos conteúdos escolares em sala de aula, ajudando o docente a criar estratégias pedagógicas e assim facilitar o processo de ensino e aprendizagem. É fundamental integrar a televisão e o vídeo na educação escolar. Segundo Freire (2005, p. 82) “o homem aumenta sua percepção à medida que reflete sobre o mundo, fazendo com que seus problemas tornem-se desafios".

O vídeo digital trabalhado como recurso didático, enfatizando conteúdos abordados do programa de conteúdos da grade curricular é importante porque desenvolve a habilidade dos discentes quanto à utilização de ferramentas da tecnologia da informação e comunicação, além de softwares para toda organização e planejamento das edições de imagens e sons. 


\section{O ensino de ciências na escola}

O ensino de ciências na escola brasileira sempre foi em grande parte um ensino descontextualizado, distante da realidade dos conhecimentos prévios dos discentes, ficando apenas na teorização de informações científicas, fazendo com os mesmos são compreendam a importância das ciências em sua vida cotidiana, tornando-se assim passivos diante às situações vivenciadas em sociedade; desmotivando os discentes no ensino de ciências, que em sua cultura escolar começaram a conceituar as aulas dessas disciplinas como "difíceis" de se aprender.

Certamente não será o modelo de ensino por transmissão do conhecimento como um ornamento cultural para legitimar uma determinada posição social de exclusão da maioria que propiciará a formação de cidadãos conscientes de seu papel na sociedade científica e tecnológica. Nem seriam também livros didáticos - sobrecarregados de conteúdos e socioculturalmente descontextualizados, que apenas ilustram as maravilhas das descobertas científicas, reforçando a concepção de que os valores humanos estão a reboque dos valores de mercado - que iriam contribuir para a formação de cidadãos críticos. Nesse sentido, mais importante do que a discussão terminológica entre alfabetização e letramento está à construção de uma visão de ensino de ciências associada à formação científico-cultural dos alunos, à formação humana centrada na discussão de valores. (SANTOS, 2007, p. 488)

Os objetivos do ensino de ciências na educação básica visam levar aos discentes uma educação e alfabetização científica, proporcionando uma compreensão crítica do meio social, ambiental, e cultural, além de estudar a importância da ciência para o desenvolvimento social e formação da cidadania e contribuição para melhoraria da qualidade de vida das pessoas. Para Taglieber (1984, p. 95-96), “em outras palavras, não é necessário somente ensinar os conceitos científicos, mais principalmente como estes conceitos e princípios foram descobertos - o processo científico de inquirição, a natureza do conhecimento científico".

A ciência está presente na vida humana a todo instante e a escola precisa introduzir a cultura científica em todos os níveis da educação básica, formando um discente crítico, capaz de compreender, conhecer e aprimorar os conceitos científicos, executando na prática e com isso se desenvolvendo com um saber científico capaz de contribuir para a sociedade. A ciência é algo impregnado na cultura humana e jamais poderá ser desvinculada dela. 
Destes objetivos gerais cada sistema escolar ou escola individual professor ou mesmo cada disciplina científica deverá desenvolver objetivos específicos para o ensino de ciências. Embora, à primeira vista os objetivos pareçam de fundamental importância para 0 desenvolvimento de um ensino eficaz a realidade prática é bem outra. (TAGLIEBER, 1984, p. 94)

Porém, o que se constata e observa-se em grande parte da educação básica é um ensino de ciências segmentado, tendo como foco principal a transmissão de conteúdos, formando o discente para ser mero receptor de informações, não tendo nenhuma ação prática diante das disciplinas científicas. De acordo com Taglieber (1984, p. 94), "havia claramente sobrecarga de conteúdos nos programas de ciências com ideias secundárias e periféricas de aplicações tecnológicas associadas a uma metodologia de ensino que induzia à memorização e se esquecia da compreensão e aplicação dos conhecimentos". O vídeo digital como recurso didático e pedagógico no ensino de ciências.

A utilização do vídeo digital como recurso didático no ensino de ciências é uma ferramenta importante, podendo despertar nos discentes um caráter lúdico em sua utilização e dinamização no trabalho didático com os conteúdos escolares. O uso e produção do vídeo digital em sala de aula pelos discentes é um importante meio de se trabalhar a comunicação de conceitos científicos, também podendo ser considerado uma ferramenta de promoção da educação científica e da construção de conhecimentos e de interpretação de temas científicos no contexto do ensino de ciências. Para Belloni e Gomes (2008, p. 734), “[...] o vídeo, como suporte pedagógico, estimula as crianças a mobilizarem seus referenciais televisuais, suas competências específicas de leitura televisual, gerando grande motivação, inclusive para outras aprendizagens como a da leitura.".

O uso do vídeo digital ou outras formas de utilização de mídias digitais favorece o trabalho docente na proposta pedagógica na transmissão de conhecimento no contexto escolar, pode ser uma importante ferramenta de aprendizagem a ser utilizada em sala de aula. Segundo Moran, (1995, p. 27) “o vídeo é sensorial, visual, linguagem falada, linguagem musical e escrita. Linguagens que interagem superpostas, interligadas, somadas, não separadas. Daí a sua força”. A sua utilização por si só não resolve o trabalho docente, porém usado como um instrumento, que auxilia, motiva, desperta a ludicidade e o trabalho coletivo, englobando uma proposta de medicação com a cultura digital, pode melhorar a construção de saberes e interação nos discentes. De acordo com 
Freire e Rangel (2012, p. 57), “o desenvolvimento da tecnologia digital tornou possível um novo modelo de comunicação, cuja estrutura, ao menos em tese, é mais dialógica".

O uso de toda uma gama de ferramentas dentro do contexto de sala de aula objetiva aumentar a motivação, tanto de professores quanto de alunos, já que possibilita uma interação diferenciada, mais constante, na medida em que amplia as possibilidades de contato entre educandos e educadores, não mais restrito apenas ao ambiente escolar. (TEIXEIRA, 2011, p. 161)

Uma nova metodologia e estratégia surgem para os docentes, fazendo com que os mesmos renovem seus métodos didáticos, e enriqueçam as possibilidades de inovação pedagógica, assim trazendo os discentes para esse contexto de mediação e participação em sala de aula, aumentando a motivação de toda comunidade escolar, propiciando uma maior participação nas propostas pedagógicas.

\section{Produção dos vídeos digitais}

A etapa de produção suscitou o uso do aparato tecnológico para edição do vídeo e finalização do produto que foi gravado em DVDs, resultando em quatro DVDs com apresentações multimídias para socialização do conhecimento produzido e estudado, além das experiências colaborativas de aprendizagem vivenciadas.

As equipes foram divididas em quatro grupos de trabalhos e a produção para exploração dos aplicativos Windows Movie Maker e Vivavídeo. Então os projetos seguiram toda uma estrutura organizacional, com algumas ferramentas tecnológicas, visando à produção do vídeo digital, em arquivo ${ }^{2} \mathrm{AVI}$, fotos e músicas para produção de trilhas sonoras. Para narrações de voz, foram utilizadas algumas estratégias de conexão e uso do microfone do smartphone; a filmagem se deu através da câmera de vídeo do próprio smartphone.

Os discentes também realizaram pesquisas de aprofundamento do assunto em estudo. A organização do roteiro foi essencial para a produção, escolhas de cenas, sons e imagens e estruturação de papéis.

No vídeo digital "ondas sonoras eletromagnéticas", a equipe mostrou na produção algumas situações práticas referentes ao tema estudado. O vídeo começa com

${ }^{2}$ O AVI, sigla em inglês para Audio Video Interleaved, é um formato que combina dados de áudio e vídeo em um arquivo para a reprodução sincronizada de ambos. Definição de AVI disponível em https://www.apowersoft.com.br/o-que-e-o-avi.html acesso em 09 de fevereiro de 2017. 
uma breve introdução do assunto feito através de cartazes, figuras expositivas, seguidas de explicação. O vídeo caracteriza-se como uma teleaula, através de explicações teóricas e algumas situações práticas. Segundo Saldanha (2013, p. 08), "Esse formato não é o de um programa televisivo nem de uma aula presencial, mas nem por isso deixa de ser um espaço/tempo de ensino-aprendizagem". Tendo como apresentador os discentes, que ao mesmo tempo também interagiam apresentando as etapas práticas. $\mathrm{O}$ vídeo digital produzido consegue trazer a contextualização do conteúdo estudado, mesmo de forma breve e resumida, faz uma ligação entre a teoria e a prática: transformam a teoria estudada em exemplos práticos e as simulações apresentadas e trazidas por eles faz com que o assunto fique claro e assimilado, expandindo assim os conhecimentos produzidos pelos discentes diante do tema ondas sonoras e eletromagnéticas. No vídeo digital com o tema "Biodiversidade", a equipe intitulou de (Biope), em referência à biodiversidade de Pernambuco. A produção traz uma abordagem caracterizada em formato de documentário, onde os discentes trazem informações relevantes da questão ambiental da cidade de Itapissuma - PE, local onde foram realizadas as filmagens. Cada integrante apresentou um assunto sobre a biodiversidade local, simulando repórteres.

O vídeo digital conseguiu trazer em sua abordagem elementos contextualizadores, já que a produção trata-se de um documentário, mostrando fatos da realidade cotidiana de um determinado lugar. A equipe interliga o tema teórico biodiversidade com situações práticas ocorridas na cidade, indo a campo, vivenciando toda experiência do conteúdo do ensino de ciência. Conseguiram estabelecer uma relação ao mesmo tempo crítica, mostrando os pontos negativos que afetam a biodiversidade local, mas também mostraram as belezas e a importância de se preservar o meio ambiente, essa junção de concepções distintas perante o tema foi muito interessante e deixou o vídeo digital coerente. Os discentes trouxeram informações e curiosidades relevantes sobre o tema, contribuindo assim para a divulgação e construção do conhecimento contextualizado.

O vídeo digital da equipe 3 , conteúdo reprodução dos seres vivos, caracteriza-se como uma teleaula. Os discentes organizaram um cartaz com curiosidade de alguns animais com imagens, fazendo uma leitura resumida da vida de cada animal pesquisado. Porém, os mesmos não conseguiram contextualizar o conteúdo, apresentando somente a parte teórica estudada em sala de aula e pesquisada em livros e internet, com uma 
simples explanação teórica do assunto e ainda mediada com leitura fixada no smartphone.

O cenário escolhido pelos discentes foi o pátio da própria escola. A equipe colocou alguns efeitos na produção visando deixar o vídeo mais dinâmico, no entanto, faltou explorar mais a parte prática do conteúdo reprodução dos seres vivos. A edição do vídeo foi feita por meio do aplicativo Vivavídeo, pelo próprio aparelho de smartphone. O vídeo teve a duração de cinco minutos e quinze segundos.

O vídeo digital 4 traz em sua abordagem o conteúdo Doenças sexualmente transmissíveis - DST; a equipe fez uma abordagem sobre a transmissão do vírus da AIDS e sua forma de contaminação por meio de relação sexual sem prevenção. Na produção a equipe criou em seu planejamento de roteiro, cinco cenários. O laboratório da escola foi utilizado como cenários em duas situações, a primeira como a festa (balada) e como cenário para explanação final do assunto. Outro cenário foi a casa de uns dos discentes, que foi utilizado em outras três situações distintas. O vídeo caracteriza-se como curta-metragem, pois apresenta uma dramatização tentando mostrar uma situação prática do tema DST em formato de história, contando uma situação ocorrida no cotidiano.

A equipe aborda um conteúdo e consegue fazer uma relação teórica e prática ao mesmo tempo, produzindo um vídeo digital de bastante relevância social por se tratar de um tema polêmico e presente na vida cotidiana de muitas pessoas; através de uma dramatização de uma situação vivenciada por muitas pessoas, trouxeram informações sobre a doença da AIDS, contribuindo para a divulgação e construção do conhecimento contextualizado. O vídeo digital produzido consegue contextualizar o conteúdo curricular estudado. 
FIGURA 6: Situações contextualizadas trazidas pelos discentes
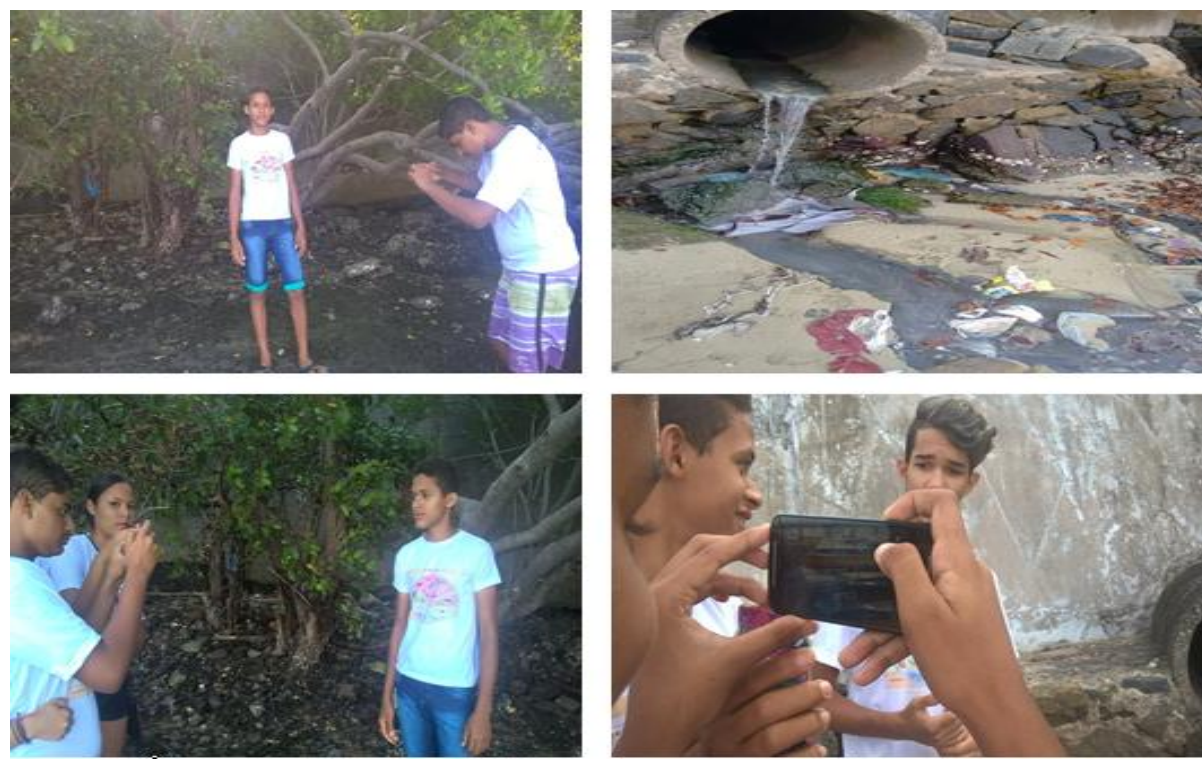

Fonte: Acervo pessoal

FIGURA 7: Bastidores da gravação do vídeo digital formato teleaula (editar)

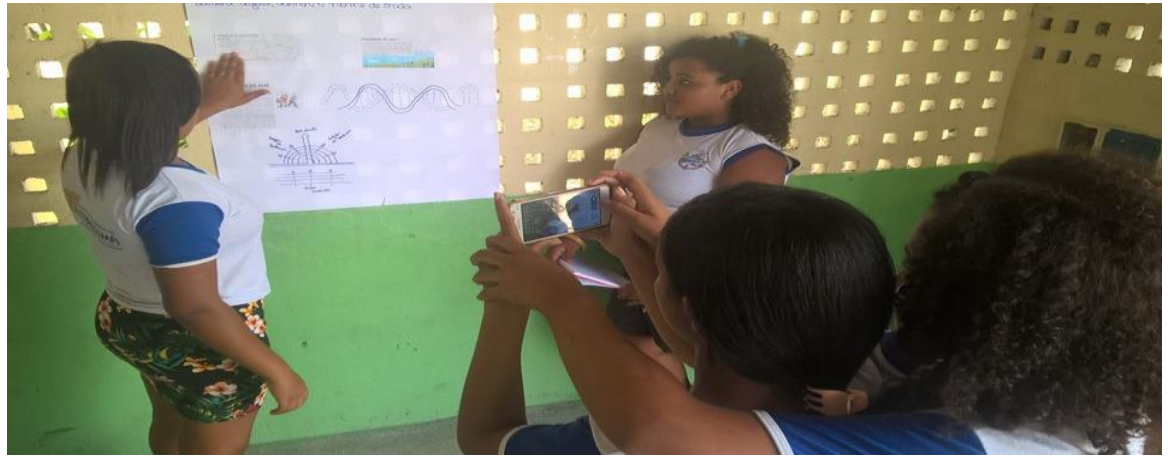

Fonte: Acervo pessoal

\section{PERCURSO METODOLÓGICO}

A pesquisa foi realizada em campo escolar na cidade de Itapissuma - PE, entre os meses de agosto a dezembro de 2016, aliando aspectos qualitativos, mediante participação, observação e intervenção direta do pesquisador junto aos discentes do $9^{\circ}$ ano do ensino fundamental. Para tal, realizaram-se oficinas de produção e planejamento dos vídeos, assim como observação da convivência e produção multimídia das equipes.

A Escola municipal que oferece os anos finais do Ensino Fundamental está localizada no centro da cidade. Segundo dados extraídos na própria instituição, a escola funciona nos três turnos, com turmas de Ensino Fundamental anos Finais e educação de 
jovens e adultos. A primeira visita ao campo de pesquisa aconteceu no dia 17 de agosto de 2016, visando conhecer o docente da disciplina do ensino de ciências e o perfil das turmas. Neste primeiro encontro o objetivo foi explicar a pesquisa ao docente e a apresentar a proposta do estudo, iniciando assim a pesquisa de campo.

Cada equipe participou da oficina de confecção de vídeo digital denominada de (oficina cultura científica e as tecnologias digitais). Os participantes da pesquisa, 18 discentes do $9^{\circ}$ ano, dividido em 4 equipes, tiveram como função produzir vídeos digitais sobre um conteúdo trabalhado em sala de aula na disciplina de Ciências, podendo ser este: (curtas-metragens, documentários, séries, talk shows, etc.), ficando cada equipe com um conteúdo curricular solicitado pelo professor da disciplina de ciências: Ondas Sonoras e Eletromagnéticas, Reprodução dos seres vivos, Biodiversidade e Doenças Sexualmente Transmissíveis.

A escolha do tipo de produção audiovisual a ser utilizada ficou a critério dos discentes, de acordo com sua criatividade. O outro sujeito da pesquisa (1) docente da disciplina de ciências ficou responsável por ser o mediador das divisões das equipes, sorteio dos conteúdos da disciplina de ciências e avaliação das produções realizadas ao longo do processo.

No início da oficina cada discente recebeu um termo de autorização de uso de imagem para os pais assinarem, liberando o uso das imagens dos mesmos para produção, sendo os mesmos orientados a devolver os termos assinados no dia de realização da produção (campo para filmagem).

\section{Materiais}

As atividades aconteceram no laboratório da escola, utilizados recursos tecnológicos de mediação, como laboratório da escola, sala de aula dos discentes, tablet, smartphone e sua filmadora, Pendrive, computadores, notebooks com o sistema operacional Windows 8, aplicativo do Windows Movie Maker, e o aplicativo Vivavídeo, disponibilizado e utilizado por alguns discentes no próprio smartphone.

\section{O aplicativo Windows Movie Maker e o VivaVídeo}


Os aplicativos de edição e produção de vídeo digitais utilizados pelos discentes foram dois, o Windows Movie Maker, que, segundo Souza, Carvalho e Moita, (2011, p. 33), "é um simples mas bem potente software de edição de vídeo, sendo ainda em parte desconhecido como interface gratuita do sistema operacional Windows". E o aplicativo

Vivavídeo, que segundo Freitas (2016, p.598-599):

O aplicativo VivaVídeo está disponível para as plataformas Android e iOS e permite ao usuário criar e editar vídeos a partir de mídias da biblioteca do celular. Recheado de recursos que vão de efeitos especiais a inserção de música nos vídeos, o aplicativo transforma o aparelho em uma poderosa central de produção audiovisual. A navegação dentro do aplicativo é bem simples. A tela inicial apresenta as opções de Captura, Filme de Fotos, Editar, Videoclipe, Estúdio, Materiais, Colagem e Em Destaque.

Esses dois aplicativos foram utilizados pelas equipes de maneira muito exitosa, dinâmica, criativa e interativa, sendo muito úteis no processo de produção. $O$ Vivavídeo, por ser um aplicativo presente nos smartphone e na vida cotidiana dos discentes, acabou sendo utilizando forma muito eficiente, não apresentado dificuldade no manuseio. Porém, com o Windows Movie Maker alguns discentes apresentaram algumas dificuldades, por ser um aplicativo com muitas informações e interatividade, em alguns momentos os mesmos tiveram dificuldades, mas conseguiram finalizar todo processo de edição.

\section{Instrumentos e procedimentos para a coleta}

A realização do presente estudo e a análise de seus desdobramentos se inserem nos pressupostos metodológicos de uma investigação de pesquisa qualitativa que na concepção de Ludke e André (1986, p. 13) “envolve a obtenção de dados descritivos, obtidos no contato direto do pesquisador com a situação estudada, enfatiza mais o processo do que o produto e se preocupa em retratar a perspectiva dos participantes".

A pesquisa foi do tipo intervenção participante. Serrano e Collazo, (1992,p.285) afirmam que "o processo participante na investigação nasce do esforço de concretizar a promoção do ser humano de forma participante e organizada”. Na pesquisa participante os sujeitos tornam-se participantes de todo o processo pedagógico de construção do saber, agindo, atuando de forma ativa diante de determinado objeto e assimilando esses 
conhecimentos para serem utilizados na prática em determinada situação cotidiana ou pedagógica. Para essa pesquisa não iremos referenciar os sujeitos por seus nomes verdadeiros, mas por pseudônimo.

A intervenção foi realizada junto aos 18 discentes do $9^{\circ}$ ano do ensino fundamental, anos finais, para orientação e procedimentos técnicos referentes à produção e proposição pedagógica do vídeo digital e uso dos aplicativos propostos. A pesquisa foi fundamentada em três procedimentos de coletas de dados.

Os sujeitos da pesquisa (discentes) tiveram a oportunidade de conhecer todas as etapas que compõem uma produção de um vídeo digital (pré-produção, produção, pósprodução, contextualização e preparação do vídeo), planejamento da roteirização e da narratividade, processo de gravação, dramatização e técnicas de edição.

\section{RESULTADOS E DISCUSSÃO}

\section{O uso do vídeo digital e a construção do conhecimento contextualizado}

A equipe ondas Sonoras e eletromagnéticas - Vídeo 1, referente à produção do vídeo digital e as contribuições para a construção do conhecimento contextualizado no ensino de ciências. Para a discente Ana Paula, o uso do vídeo digital em sala de aula "trouxe sim contribuições para a construção do conhecimento contextualizado no ensino de ciências porque para produzir o vídeo foi preciso estudar mais e isso melhora a aprendizagem." Já a discente Jéssica destaca que o uso do vídeo “traz sim contribuições porque segundo ela fala-se sobre o assunto e se aprende mais, porque fala de ciências e com isso o professor dando o assunto nas aulas fica mais fácil entender o assunto". A discente Mariele relata que "produzir um vídeo digital traz contribuições para a construção do conhecimento contextualizado porque é uma forma de conhecimento para a vida, é uma forma de dar mais ensino”. Já para a discente Mariana, "a produção do vídeo traz contribuição porque se está explicando e mostrando as ondas sonoras na prática. O vídeo ajuda a entender o assunto". A discente Simone conclui destacando que "a produção do vídeo digital traz contribuição porque segundo ela deu pra entender melhor o assunto, fazendo o vídeo. Com o vídeo e produzindo se entende melhor com as explicações ajudando no conhecimento”. 
Segundo a equipe 1 , o trabalho com a produção de vídeo digital no ensino de ciências trouxe contribuições na construção do conhecimento contextualizado, pois vivenciaram algumas situações práticas que ajudaram no entendimento no conteúdo estudado.

\begin{abstract}
É possível generalizar a contextualização como recurso para tornar a aprendizagem significativa ao associá-la com experiências da vida cotidiana ou com os conhecimentos adquiridos espontaneamente. É preciso, no entanto, cuidar para que essa generalização não induza à banalização, com o risco de perder o essencial da aprendizagem escolar que é seu caráter sistemático, consistente e deliberado. Em outras palavras: contextualizar os conteúdos escolares não é liberá-los do plano abstrato da transposição didática para aprisioná-los no espontaneísmo e na cotidianeidade. (BRASIL, 1999, p. 94)
\end{abstract}

Tudo isso reforça a tese que estamos sustentando nessa pesquisa, que a produção de vídeo digital no contexto escolar traz importantes contribuições para a construção cognitiva em sala de aula, ajudando a melhorar a assimilação do conteúdo, promovendo uma motivação e interesse pelo assunto, pelas aulas, fazendo com que os discentes consigam entender melhor o assunto estudado.

\begin{abstract}
Acrescenta-se que as teorias e práticas associadas à informática na educação vêm repercutindo em nível mundial, justamente porque as ferramentas e mídias digitais oferecem à didática, objetos, espaços e instrumentos capazes de renovar as situações de interação, expressão, criação, comunicação, informação, e colaboração, tornando-a muito diferente daquela tradicionalmente fundamentada na escrita e nos meios impressos. (SOUZA, CARVALHO e MOITA, 2011, p. 22)
\end{abstract}

Conseguindo relacionar a teoria com a prática, consequentemente se constrói um conhecimento e o entendimento dos discentes, promovendo um protagonismo e autonomia que os mesmos adquiriram durante o processo da pesquisa. $\mathrm{O}$ estudo e a produção do vídeo digital ajudaram muito no entendimento do que o docente quis passar na sua aula, pois ao mesmo tempo em que o discente estava na sala vendo a explicação do docente, com a produção, ele ampliava ainda mais a compreensão do conteúdo porque começava a entrar em contato direto com o conteúdo através das situações práticas que elaboraram seguindo a teoria do assunto.

A equipe Biodiversidade - Vídeo 2, com relação às contribuições para a construção do conhecimento contextualizado, o discente João afirma que a produção do vídeo traz contribuições "porque foi um tema legal e me ajudou muito a entender a 
matéria. $O$ vídeo me fez entender mais sobre o assunto indo além da explicação do professor". O discente Vitor destaca que "trouxe muita contribuição. Porque aprendemos que a poluição prejudica a vida das pessoas, mostrando a realidade da poluição e do desmatamento. E isso contribui muito no ensino de ciências". A discente Monica relata "trouxe sim contribuição. Porque a gente aprendeu mais, porque o vídeo produzindo é melhor do que um livro, porque com o livro fico entediado”. Já o discente Rafael fala que o uso do vídeo "ajudou na matéria de ciências, porque na prática ajudou muito, também me interessei e aprendi mais, tive mais confiança no professor e na matéria”. E o discente Mario destaca que a produção dos vídeos traz contribuição, "porque a gente aprendeu, assistindo e escutando, melhora o aprendizado da gente, melhor do que ler um livro, bem melhor estudando e criando o roteiro, ajuda a entender melhor o assunto". Relacionamos as afirmações dos discentes com a concepção que Moran (1995, p. 28) traz sobre a importância do vídeo, quando ele destaca que:

O vídeo é sensorial, visual, linguagem falada, linguagem musical e escrita. Linguagens que interagem superpostas, interligadas, somadas, não separadas. Daí a sua força. Somos atingidos por todos os sentidos e de todas as maneiras. O vídeo nos seduz, informa, entretém, projeta em outras realidades (no imaginário), outros tempos e espaços. O vídeo combina a comunicação sensorial-cinestésica com a audiovisual, a intuição com a lógica, a emoção com a razão. Combina, mas começa pelo sensorial, pelo emocional e pelo intuitivo, para atingir posteriormente o racional.

A função pedagógica da produção de um vídeo digital é vasta, conseguindo desenvolver várias competências justamente por conta de todo dinamismo que ele apresenta em sua essência. De acordo com Schneider e Ribeiro, (2012, p.3) "a tecnologia está cada vez mais presente na vida dos alunos e em virtude desse dinamismo, a produção de vídeos digitais de curta duração está cada vez mais popular”. O vídeo em si, seja em qual formato for, consegue seduzir, por conta de vários fatores, como imagens, sons, efeitos, cores e toda linguagem existente nele. Já diante da etapa de uma produção de um vídeo digital essa sedução aumenta mais ainda, pois quem vivencia essa experiência se depara com um processo de interação, colaboração, trabalho em equipe, organização, o saber ouvir e linguagem, bastante presente, os elementos do teatro também estão presentes nesse processo.

Por isso, a produção em si desenvolve muito os discentes envolvidos. Diante disso Schneider, Caetano e Ribeiro (2012, p. 03) destacam que "o vídeo tem um poder 
de ilustração muito forte, prende atenção quando bem estruturado e elaborado. Tem movimento, áudio e, muitas vezes, é autoexplicativo".

Segundo os discentes, a produção de vídeo digital no contexto escolar traz importantes contribuições para a construção do conhecimento contextualizado no ensino de ciências, despertando a aprendizagem, a confiança no docente e na matéria e o interesse pelo assunto. $\mathrm{O}$ vídeo tem um grande poder de influência sobre os discentes, pois sua fundamentação e estruturação faz com que a atenção dos mesmos seja fixada, trazendo-os para um universo mais ilustrativo e interativo.

A equipe Reprodução dos seres vivos - Vídeo 3, sobre as contribuições para a construção do conhecimento contextualizado, o discente Caio destaca que a produção do vídeo traz contribuições, segundo ele “ajudou a entender mais da vida dos animais". O discente Bruno enfatiza que contribui "sim, porque trouxe mais informações sobre os animais". O discente Paulo fala que "foi uma experiência, porque mostrou muita curiosidade no ensino de ciências. Por isso expandiu o sentimento diante da matéria, também ajudou na disciplina”. Já o discente Roberto diz que a produção do vídeo “ajudou não. Porque eu já sabia do assunto”.

Para o discente Cesar "ajudou, porque fiquei focado no trabalho, em fazer algo certo e não fazer ruim. Aprendi mais o assunto, prestei mais atenção no assunto”. E o discente Sérgio relata que "ajudou na aprendizagem do assunto, porque ajudou na hora da prova, tudo que estudamos no vídeo caiu na prova e isso me ajudou muito”.

Diante das afirmações dos discentes trazemos a discussão Moran, Masetto e Behrens, (2012, p. 08) que fala que "saber pesquisar, escolher, comparar e produzir novas sínteses, individualmente e em grupo, é fundamental para ter chances na nova sociedade que estamos construindo”. Sendo assim, Moran, Masetto e Behrens (2012) reforçam a importância da pesquisa, interação, da seleção e escolha de estratégias a serem utilizadas na produção do saber, todos esses fatores sendo fundamentais nesse cenário atual em que estamos vivendo.

Diante dessa discussão, Sancho (1998,p.39) destaca que "as tecnologias usadas no ensino escolar, modelam o desenvolvimento dos indivíduos e a sua forma de apreensão do mundo". Mediante tal discussão podemos dizer que um trabalho escolar desenvolvido por meio da produção de um vídeo digital desperta no discente uma expansão de concepção de mundo, despertando um interesse e curiosidade em sala.

Porém, a mediação docente diante esse processo de utilização das tecnologias digitais e outras práticas pedagógicas é de suma importância para o sucesso dessa 
metodologia de ensino. Diante disso Silva e Oliveira (1981, p. 05) enfatizam que o "uso do vídeo em sala de aula acaba norteando habilidades diversificadas mediante a formação do aluno como, por exemplo, desenvolver a interação entre os sujeitos. Haja vista que essa mídia educacional viabiliza uma prática mais atrativa e conteúdos contextualizados".

O uso da produção de vídeo digital segundo os discentes ajuda no entendimento do conteúdo estudado, aumentando o interesse pelas aulas, a pesquisa e leitura, como também a interação entre eles. Cada vez mais utilizado de maneira adequada, o uso do vídeo na escola será uma importante metodologia pedagógica atrativa e dinâmica, pois sua utilização visa sempre expandir o conhecimento na relação teórica e prática, assim desenvolvendo a contextualização de conteúdos.

A Equipe doenças sexualmente transmissíveis - DST Vídeo 4, com relação a contribuições para a construção do conhecimento contextualizado, a discente Gabriele fala que a produção do vídeo traz contribuições para a construção do conhecimento contextualizado no ensino de ciências, "por que a gente estudou para fazer o vídeo, o assunto fica muito mais visível e como para produzir o vídeo é preciso estudar o assunto fica mais assimilado”. Já para a discente Vanessa a produção do vídeo traz sim contribuições, "por que a gente aprende em sala de aula o professor explicando. Já no vídeo agente que ensina o que agente aprendeu em sala de aula, tivemos que aprender para passar para o pessoal através do vídeo".

Para os discentes, a produção do vídeo trouxe contribuições para a construção do conhecimento contextualizado no ensino de ciências, porque houve estudo por parte dos discentes para fazer o vídeo, ficando o assunto muito mais visível e fácil de assimilação. Aprende-se em sala de aula com o docente explicando, e no vídeo se ensina o que se aprendeu em sala de aula: foi preciso aprender para passar para o pessoal através do vídeo. Pimenta e Ghedin (2002, p. 97) destacam que “ensinar não é a mesma coisa que fazer aprender, ainda que, muitas vezes, para fazer o aluno aprender, o professor tenha que ensinar". A equipe desenvolveu uma qualidade essencial para o crescimento intelectual deles, que foi a questão da autonomia, o senso participativo e dialógico que demostraram foi notável e de muita eficiência na organização da produção. Diante dessa análise, Freire (2010, p.18) enfatiza que "a ligação mais forte do saber pensar é a gestação da autonomia".

Para os discentes a produção do vídeo digital ajudou na assimilação do conteúdo, ao mesmo tempo em que se ensinava se aprendia, e essa interação ajudou no 
entendimento do assunto estudado. Por isso, a produção do vídeo digital trouxe importantes contribuições para a expansão do conhecimento contextualizado.

\section{Considerações finais}

Neste estudo, apresentamos como discussão a contribuição da produção de vídeos digitais na construção do conhecimento contextualizado no ensino de ciências. Resumida na problemática de que a produção do vídeo digital pode trazer algumas contribuições para os discentes na construção do conhecimento prático, estimulando várias competências e habilidades, promovendo alguns saberes mediante o processo de produção do vídeo, como autorrepresentações pelos próprios sujeitos que participaram da experiência, no esforço para resolver um determinado problema, tornando assim discentes realizadores e produtores de conhecimento por meio da produção do vídeo digital. Essa pesquisa utilizou os procedimentos de uma pesquisa qualitativa do tipo intervenção participante, fundamentando-se em três procedimentos de coletas de dados, questionário, observação participante e entrevista. A pesquisa contou com a participação de 18 sujeitos.

Diante dessas discussões, definimos essa pesquisa partindo do seguinte questionamento: Que contribuições pode trazer a produção de vídeos digitais por discentes de uma escola municipal para a construção do conhecimento contextualizado no ensino de ciências?

Essa inquietação foi uma das propulsoras para o desenvolvimento dessa pergunta, tentando no conjunto de procedimentos adotado no estudo, responder à questão. Trazer para o contexto escolar uma educação contextualizadora, estimulando os discentes por meio da produção audiovisual com o uso das tecnologias digitais, é algo inovador e de grande contribuição social.

Os resultados mostraram que os discentes alcançaram a construção dos conhecimentos contextualizados no ensino de ciências através da produção do vídeo digital, promoveram articulações através dos conhecimentos revelados na produção do vídeo digital, tais como trabalho colaborativo, senso organizacional, planejamento, estratégias de estudo através de pesquisas e leitura, e realizaram mobilizações visando à construção dos conhecimentos adquiridos no ensino de ciências através de habilidades como criatividade, organização, comprometimento, planejamento, trabalho cooperativo, divulgação e debate na internet, especificamente nas redes sociais. 
Com isso a pesquisa traz uma grande contribuição para a produção de vídeo e toda sua metodologia técnica e pedagógica no contexto educacional, como ferramenta auxiliar na construção do conhecimento contextualizado no ensino de ciências para a maioria dos discentes. Um resultado que reforça a discussão sobre o uso e produção da linguagem cinematográfica como instrumento educacional.

Espero com esses resultados colaborar viabilizando as discussões sobre a contribuição do vídeo digital e o uso das tecnologias digitais no processo de construção cognitiva, a importância da produção do vídeo no contexto escolar e o seu poder pedagógico diante dos discentes, tendo em vista que a produção proporcionou aos discentes um olhar mais crítico perante o conteúdo estudado, uma maior motivação na construção do conhecimento contextualizado no ensino de ciências por discentes do ensino fundamental nos anos finais em uma escola municipal, com a finalidade de elevar o interesse pelas aulas, um senso organizacional e de planejamento do conteúdo estudado, estimulando o senso colaborativo, autônomo e um protagonismo estudantil, objetivando uma ação educativa que potencialize a construção do conhecimento contextualizado. Tudo isso resultou na produção cultural dos vídeos, a troca de informações e principalmente uma participação significativa dos sujeitos nas dinâmicas sociais e contemporâneas que essa experiência proporcionou.

A partir da análise fica evidenciada que a produção de vídeos digitais promoveu nos discentes uma construção cognitiva mais significativa e real, despertando neles um maior dinamismo na busca de informações de forma crítica e criativa na elaboração do vídeo. Os discentes construíram uma nova forma de entender o conteúdo estudado em sala, novos aprendizados e novas formas de compreensão através dessa metodologia de produção audiovisual.

\section{REFERÊNCIAS}

BRASIL. Referenciais para a formação de professores. Ministério da Educação Secretaria de Ensino Fundamental. Brasília. 1999. Disponível em: <http://www.dominiopublico.gov.br/download/texto/me002179.pdf >. Acesso em: 10 jan. 2016.

BELLONI, M. L.; GOMES, N. G. Infância, mídias e aprendizagem: autodidaxia e colaboração. Revista Educação \& Sociedade, v. 29, n. 104 - Especial. p. 717 - 746, out. 2008. p.734.

FREIRE, P. Pedagogia do oprimido. Rio de Janeiro: Paz e Terra, 2005. 
FREIRE, P. Pedagogia da autonomia. São Paulo : Paz e Terra, 2010.

FREIRE, W.; RANGEL, M. Educação e tecnologia: texto, hipertexto e leitura. Rio de Janeiro: Wak, 2012.

MARCONDES FILHO, C. Televisão: a vida pelo vídeo. São Paulo: Moderna, 1995.

MORAN, J. M.; MASETTO, M. ; BEHRENS, A. Novas tecnologias e mediação pedagógica. 19. ed. Campinas, SP: Papirus, 2012.

MORÁN, J. M. O vídeo na Sala de aula. Comunicacão e Educacão, São Paulo, (2): 27 a 35,.jan./abr. 1995.

PIMENTA, S. G.; GHEDIN, E. Professor reflexivo no Brasil: gênese e crítica de um conceito. São Paulo: Cortez, 2002.

SALDANHA, L. C. D. Ateleaulaemquestão. \#Tear: Revista de Educação Ciência e Tecnologia, Canoas, v.2.n.2, 2013.

SOUZA, R. P. D.; CARVALHO, A. B. G.; MOITA, F. M. C. D. S. C.; MOITA, F. M. C da S. C.; CARVALHO,G. B. A. Tecnologias digitais na educação. Campina Grande: EDUEPB, 2011.

LUDKE, M.; ANDRÉ, M. A. Pesquisa em educação: abordagens qualitativas. São Paulo: EPU, 1986.

SERRANO, G. I.; COLLAZO, W. R. Contribuciones portorriqueñas a la psicologia social-comunitaria. Rio Piedras: Editorial de La Universidad de Puerto Rico, 1992.

SANTOS, W. L. P. Educação científica na perspectiva de letramento como prática social: funções, princípios e desafios. Revista Brasileira de Educação v. 12 n. 36 set./dez. 2007.

SILVA, F. R.; CORREIA, S. E. Novas tecnologias e educação: a evolução do processo de ensino e aprendizagem na sociedade contemporânea. Educação e Linguagem, ano 1, p. 23-25, junho 2014.

SCHNEIDER, C. K.; CAETANO, L.; RIBEIRO, L. O. Ms. Análise de Vídeos Educacionais no youtube: caracteres e legibilidade. Revista Novas Tecnologias na Educação, CINTED-UFRGS, Porto Alegre, v. 10, p. 35-39, 2012.

SANCHO, J. M. Para uma tecnologia educacional. Porto Alegre: Artmed, 1998.

SILVA, R. V.; OLIVEIRA, E. M. As possibilidades do uso do vídeo como recurso de aprendizagem de aula do $5^{\circ}$ ano. Pesquisa em educação: Desenvolvimento, ética e responsabilidade social.

TEIXEIRA, A. G. D. Um levantamento de percepções de professores sobre a tecnologia na prática docente.Linguagens e Diálogos, v. 2, p. 159-174, 2011. 
TAGLIEBER, J. E. O ensino de ciências nas escolas brasileiras. Perspectiva, Florianópolis, p. 91-111, Jul./Dez 1984.

ZUIN, A. O Plano Nacional de Educação e as tecnologias da informação e comunicação. Educ. Soc., Campinas, v. 31, n. 112, p. 961-980, jul.-set. 2010.

\section{Como referenciar este artigo}

VIEIRA, Sebastiao Silva. A contribuição da produção de vídeos digitais por discentes de uma escola municipal na construção do conhecimento contextualizado no ensino de ciências. Revista on line de Política e Gestão Educacional, Araraquara, v. 21, n. esp. 1, 755-775, out./2017. Disponível em: <http://dx.doi.org/10.22633/rpge.v21.n.esp1.out.2017.10452>. E-ISSN:1519-9029.

Submetido em: 10/04/2017

Aprovado em: 20/07/2017 